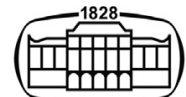

AKADÉMIAI KIADÓ

Acta Chromatographica

$33(2021)$ 4, 378-386

Dol:

$10.1556 / 1326.2020 .00824$

(C) 2020 The Authors

\section{ORIGINAL RESEARCH} PAPER

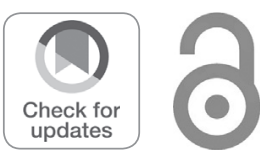

\title{
Development of a highly sensitive HPLC method for the simultaneous determination of eight biogenic amines in aquatic products
}

\author{
QINYI FU, HONGWEI ZHENG, XIANGNING HAN, \\ LIMIN CAO and JIANXIN SUI*
}

Food Safety Laboratory, College of Food Science and Engineering, Ocean University of China, 5 Yushan Rd., Qingdao, China

Received: July 28, 2020 • Accepted: September 16, 2020

Published online: October 13, 2020

\begin{abstract}
A highly sensitive high-performance liquid chromatography (HPLC) method was developed for the simultaneous determination of eight biogenic amines in aquatic products. The biogenic amines in the sample were extracted with $5 \%$ trichloroacetic acid, derived with dansyl chloride (Dns-Cl) and quantified by a UV detector. The results showed that tryptamine (TRY), 2-phenethylamine (PHE), putrescine (PUT), cadaverine (CAD), histamine (HIS), tyramine (TPY), spermidine (SPD), and spermine (SPM) were effectively separated in $18 \mathrm{~min}$ in the range of $0.1-50 \mathrm{mg} / \mathrm{kg}$ with a good linear coefficient $\left(r^{2}>0.999\right)$. The detection limits (LODs) of the eight biogenic amines were $0.007-0.021 \mathrm{mg} / \mathrm{kg}$ while the limits of quantification (LOQs) were $0.024-0.069 \mathrm{mg} / \mathrm{kg}$ with the recoveries basically between 68 and 123\%. The determination of eight biogenic amines in five commercial fermented aquatic products indicating that the developed method could be applied for the simultaneous detection of biogenic amines in multiple aquatic products.
\end{abstract}

\section{KEYWORDS}

aquatic products, biogenic amines, derivation, high sensitivity, HPLC

\section{INTRODUCTION}

Biogenic amines, which are a general term for a class of biologically active nitrogen-containing organic compounds with low molecular weight, have been found in various foods such as cheese, wine, meat and aquatic products [1]. It has reported that fresh fish have very low levels of biogenic amines, and the biogenic amines are mainly produced by the decarboxylation of amino acids with the decarboxylase generated by microorganisms during the processing or storage [2]. Fermented aquatic food, referring to the aquatic products processed and manufactured with beneficial microorganisms, is one of the traditional food types in China. Fermented aquatic food has unique flavor, but the content of biogenic amines will increase rapidly during the fermentation processing. As an essential component of biologically active cells, biogenic amines play important roles in regulating nucleic acid, protein synthesis and biofilm stability. However, excessive intake of biogenic amines might cause adverse physiological reactions such as headache, abdominal cramps, vomiting, and abnormal blood pressure [3]. Therefore, many countries and regions have established limits for biogenic amines, especially for histamine in aquatic products. The FDA recommends that the maximum limit of histamine in aquatic species is $50 \mathrm{mg} / \mathrm{kg}$, while the EU is $100 \mathrm{mg} / \mathrm{kg}$. In

${ }^{*}$ Corresponding author. Tel.: +86 053282032389.

E-mail: suijianxin@ouc.edu.cn China, the maximum limit of histamine in high-histamine fish such as mackerel is $400 \mathrm{mg} /$ $\mathrm{kg}$, and that in the other aquatic products is $200 \mathrm{mg} / \mathrm{kg}$.

Tryptamine (TRY), phenylethylamine (PHE), putrescine (PUT), cadaverine (CAD), histamine (HIS), tyramine (TYR), spermidine (SPD), and spermine (SPM) are the eight biogenic amines commonly existed in foods. In order to detect the content of biogenic amines in foods, lots of detection methods, such as liquid chromatography, thin layer 
chromatography, gas chromatography, ion chromatography, capillary electrophoresis, colorimetric method and biosensor method have been established [4-10]. High performance liquid chromatography (HPLC) was the most commonly used method for the quantitative analysis of biogenic amines because of its high detection sensitivity, good linearity, and accurate quantitative analysis. However, in the detection of biogenic amines in aquatic products, the existing HPLC methods show some disadvantages. Firstly, because most biogenic amines lack a suitable chromophore, they have to be derived with dansyl chloride (Dns-Cl), o-phthalaldehyde or other reagents before analyzing with ultraviolet or fluorescence detection, but the derivatization procedures of the existing methods are laborious and time-consuming, it even need to take 1.5-2 hours for the sample pretreatment and derivation $[11,12]$. The derivation process of the China's national standard HPLC method for biogenic amines takes more than $30 \mathrm{~min}$. Secondly, some HPLC methods cannot detect the eight biogenic amines simultaneously [13]. And more importantly, as the increasing concern to food safety, researchers want to explore the formation mechanism of biogenic amines during the processing or storage, they have to determine the biogenic amines at a very low level, but the sensitivity of the existing HPLC methods cannot meet the requirements.

Hence, in the study, a new derivatization method which was simple and time-saving was optimized and developed for the simultaneous determination of eight biogenic amines coupled to HPLC method. The sensitivity and repeatability of the developed method was finally validated and applied to the detection of biogenic amines in five kinds of fermented aquatic products.

\section{MATERIALS AND METHODS}

\section{Reagents and samples}

TRY, PHE, PUT, CAD, HIS, TYR, SPD, SPM, and Dns-Cl were purchased from Sigma-Aldrich Chemical Company (Germany). Methanol and Acetonitrile of chromatographic grade purity were purchased from TEDIA Chemical Company (USA). Ultrapure water was obtained from a Milli-Q ultrapure system (USA). All the other chemicals were purchased from Sinopharm Group (China) with analytical reagent grade.

Crucian carp, sea bass and turbot were purchased from Nanshan Fishery Market (Qingdao, China). Canned fermented fish and shrimp paste of various brands were purchased from Liqun Commercial Building (Qingdao, China).

\section{Sample preparation}

Stock solution of eight biogenic amines were prepared with 0.1 $\mathrm{mol} / \mathrm{L} \mathrm{HCl}$ to a concentration of $1,000 \mathrm{mg} / \mathrm{L}$ and stored at $-20{ }^{\circ} \mathrm{C}$. During the experiment, working solutions were prepared freshly by diluting the stock solutions to the desired concentration with $0.1 \mathrm{~mol} / \mathrm{L} \mathrm{HCl}$ and derivatized individually.

All the aquatic product samples were homogenized with a small food grade beater for $5 \mathrm{~min}$ at room temperature for the further use. Five gram of the homogenized sample was taken in a $50 \mathrm{~mL}$ centrifuge tube, mixed with $20 \mathrm{~mL}$ of $5 \%$ trichloroacetic acid solution for $10 \mathrm{~min}$ by a homogenizer (T10, IKA, German) to fully extract the biogenic amines. The mixture was centrifuged at $3,500 \mathrm{~g}$ for $20 \mathrm{~min}$ (High speed refrigerated centrifuge, Neo 15, HealForce, China), and the supernatant was transferred to $25-\mathrm{mL}$ volumetric flask and adjusted to $25 \mathrm{~mL}$. One mililiter of the solution was taken for the derivation.

\section{Sample derivation}

One mililiter of saturated $\mathrm{NaHCO}_{3}$ was added to $1 \mathrm{~mL}$ of sample solution and mixed well, after adjusting the $\mathrm{pH}$ to 9 with $1 \mathrm{~mol} / \mathrm{L}$ of $\mathrm{NaOH}, 1 \mathrm{~mL}$ of Dns- $\mathrm{Cl}$ dissolved in acetone at the concentration of $10 \mathrm{mg} / \mathrm{mL}$ was added and vibrated thoroughly. The tube was incubated in a water bath at $60{ }^{\circ} \mathrm{C}$ for $20 \mathrm{~min}$, then $3 \mathrm{~mL}$ of ether was added and vortexed for 1 min, resting for $2 \mathrm{~min}$ until the layers separated. The upper organic layer was transferred to another tube and dried under nitrogen. The residue was dissolved with $0.9 \mathrm{~mL}$ of acetonitrile and $0.1 \mathrm{~mL}$ of ammonia (25\%) was added to remove excess derivatizing agent. The sample was filtered through a $0.22 \mu \mathrm{m}$ filter (PES, $0.22 \mu \mathrm{m}$, JINTENG) for the liquid chromatography analysis.

\section{High-performance liquid chromatography (HPLC) analysis}

The HPLC analysis was performed with a HITACHI highperformance liquid chromatograph (Chromaster, HITACHI, Japan). An Agilent Eclipse Plus C18 column (4.6 $\mathrm{mm} \times 250 \mathrm{~mm}, 5 \mu \mathrm{m}$ ) was chosen for the separation of the eight biogenic amines as the follow conditions: The column temperature was set to $40^{\circ} \mathrm{C}$, the injection volume was $20 \mu \mathrm{L}$ per injection, the liquid flow rate was $1.0 \mathrm{~mL} / \mathrm{min}$ and the UV detection wavelength was $254 \mathrm{~nm}$. The gradient elution procedure consisting of acetonitrile and ultrapure water was carried as shown in Table 1.

\section{Statistical analysis}

Statistical analyses were performed using the PAWS statistics 18.0 software (SPSS, USA). The experiments were performed in triplicate and the data were expressed as average \pm relative standard deviation.

\section{RESULTS AND DISCUSSION}

\section{Optimization of derivative conditions}

Because of the lack of neither UV-visible absorption nor fluorescent effect, the biogenic amines need to be derived by some derivatization reagents such as $\mathrm{Dns}-\mathrm{Cl}$, phthalaldehyde, benzoyl chloride and so on. Among them, Dns-Cl was

Table 1. Liquid phase gradient elution procedure

\begin{tabular}{lrrrrrrr}
\hline Time (min) & 0 & 9 & 10 & 12 & 15 & 20 & 25 \\
Acetonitrile (\%) & 60 & 75 & 80 & 95 & 100 & 60 & 60 \\
Ultrapure water (\%) & 40 & 25 & 20 & 5 & 0 & 40 & 40 \\
\hline
\end{tabular}


preferred due to its stable and higher detection sensitivity for SPD and SPM [14].

It has been reported that the amount of Dns- $\mathrm{Cl}$ affected the efficiency of derivatization significantly. One molecule of Dns-Cl could derive one molecule of the amino terminal of biogenic amines theoretically, but Dns-Cl was commonly overused in practically. On the other hand, Dns- $\mathrm{Cl}$ itself has a high chromatographic peak, which would affect the quantitative calculation of biogenic amines. The excess Dns$\mathrm{Cl}$ was usually removed by adding ammonia-containing compounds such as sodium glutamate solution, proline or ammonia water after the incubation of water bath and before the extraction in the dark condition for 30-40 min, which was time consuming and difficult to ensure that the excess Dns-Cl was removed completely $[15,16]$. Therefore, in this study, the amount of Dns-Cl for the derivation was optimized and a new method for the removal of the excess of Dns-Cl was developed.

As shown in Fig. 1, the peak area of SPM at the same concentration $(10 \mathrm{mg} / \mathrm{L})$ increased with the amount of Dns-

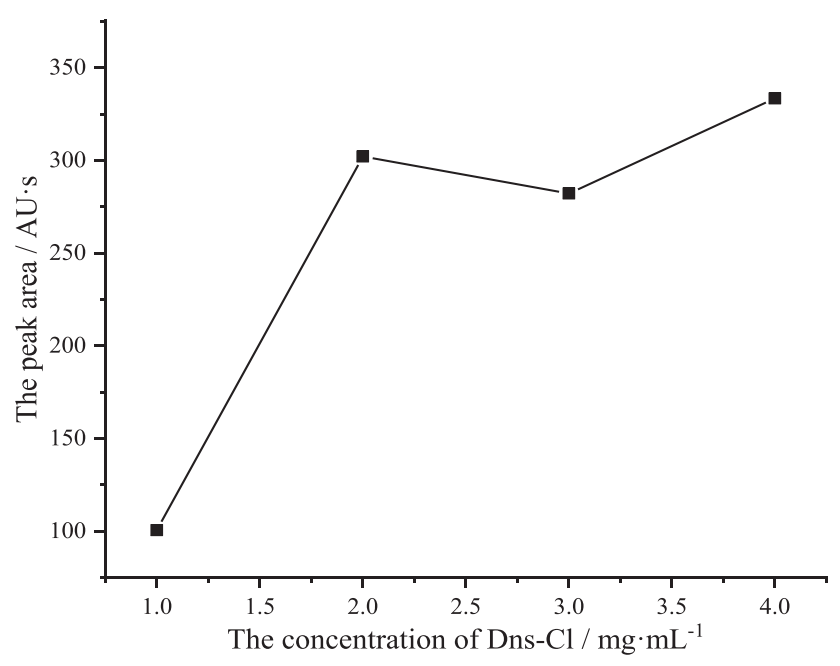

Fig. 1. Changes of SPM $(10 \mathrm{mg} / \mathrm{L})$ peak area with the amount of Dns- $\mathrm{Cl}$ added
$\mathrm{Cl}$, when the concentration of Dns-Cl reached to $2.0 \mathrm{mg} / \mathrm{mL}$, the peak area of SPM kept stable at a high value. Meanwhile, after derivatization, extraction, nitrogen drying and redissolution, ammonia water was added, and the yellow color of the solution was observed to fade rapidly, and the peak of Dns-Cl was no longer appeared in the liquid chromatogram, indicating that the excessive Dns-Cl was completely removed. The method was time saving, simple and easy to operate, which could improve the experimental efficiency significantly.

\section{Method evaluation}

Linearity, sensitivity and repeatability. After derivation at the optimal conditions described above, liquid phase analysis was carried out on each biogenic amine standard with a certain concentration to determine its peak time, and then eight biogenic amines mixed standard samples were used for the detection. The eight biogenic amines were completely separated within $18 \mathrm{~min}$ when eluted by acetonitrile and ultrapure water in a gradient elution procedure (Fig. 2). Compared with the previous methods reported by Zeng et al. [13] and Saaid et al. [17] the analysis time of the developed HPLC method in this study was shortened by about $12 \mathrm{~min}$, and it was reduced by nearly 58 min compared with that reported by Kirschbaum, et al. [18] which could improve the detection efficiency of biogenic amines significantly.

The eight biogenic amines mixed standard stocks were series diluted to validated the linearity, sensitivity, precision and accuracy of the developed methods, as shown in Table 2, the linear relationship of TRY and TYR was in the range of $0.05-50 \mathrm{mg} / \mathrm{kg}$, while the other six were $0.1-50 \mathrm{mg} / \mathrm{kg}$ with a good linear coefficient $\left(r^{2}>0.999\right)$. When calculated with the signal-to-noise ratio $(S / N)$, the detection limits (LODs) $(S / N=3)$ of the eight biogenic amines were ranged from 0.007 to $0.021 \mathrm{mg} / \mathrm{kg}$, and the limits of quantification (LOQs) $(S / N=10)$ were ranged from 0.024 to $0.069 \mathrm{mg} / \mathrm{kg}$. The LODs and LOQs are much lower than that reported by Mazzotti et al. [19] Self et al. [20] and Simat et al. [21] indicating that the method could be used to detect the biogenic amines at low levels.

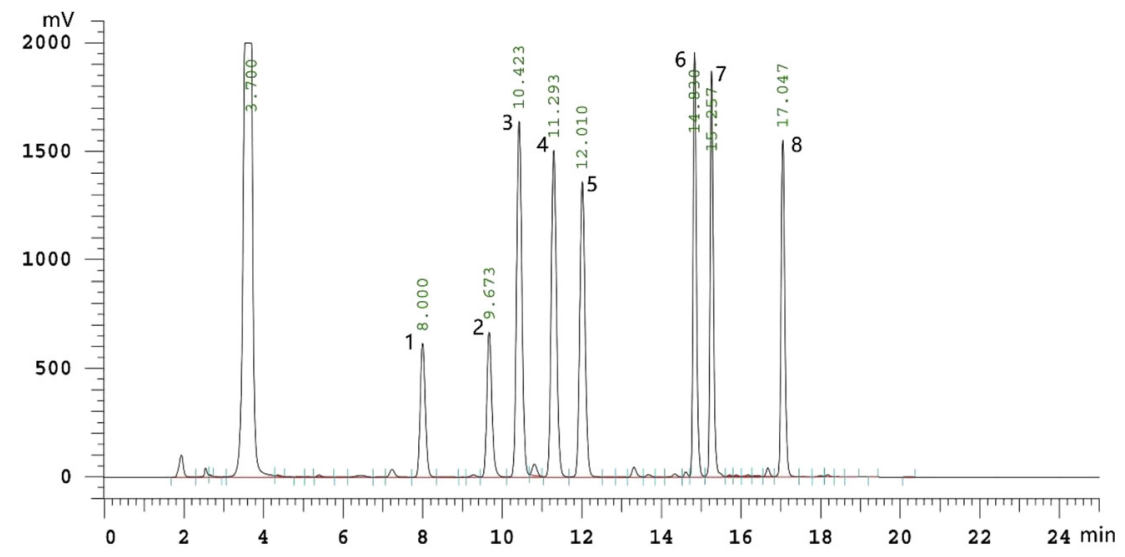

Fig. 2. Chromatogram of biogenic amine standard (50 mg/L). 1: TRY, 2: 2-PHE, 3: PUT, 4: CAD, 5: HIS, 6: TYR, 7: SPD, 8: SPM 
Table 2. The calibration curve, correlation coefficients $\left(R^{2}\right)$, linear ranges, limits of detection (LODs), limits of quantification (LOQs), and relative standard deviation (RSD) of the HPLC method

\begin{tabular}{|c|c|c|c|c|c|c|c|}
\hline \multirow[b]{2}{*}{ Biogenic amine } & \multirow[b]{2}{*}{ Calibration curve } & \multirow[b]{2}{*}{$R^{2}$} & \multirow[b]{2}{*}{ Linear range $(\mathrm{mg} / \mathrm{kg})$} & \multirow[b]{2}{*}{ LOD (mg/kg) } & \multirow[b]{2}{*}{ LOQ (mg/kg) } & \multicolumn{2}{|c|}{ RSD (\%) } \\
\hline & & & & & & Intra-batch differences & $\begin{array}{l}\text { Inter-batch } \\
\text { differences }\end{array}$ \\
\hline TRY & $y=10.228 x-4.0341$ & 1 & $0.05-50$ & $0.021 \pm 0.03$ & $0.069 \pm 0.08$ & 0.16 & 1.83 \\
\hline 2-PHE & $y=12.926 x-6.0781$ & 0.9997 & $0.1-50$ & $0.017 \pm 0.07$ & $0.058 \pm 0.11$ & 1.04 & 4.57 \\
\hline PUT & $y=34.624 x-4.72$ & 0.9993 & $0.1-50$ & $0.007 \pm 0.19$ & $0.024 \pm 0.18$ & 5.48 & 6.26 \\
\hline CAD & $y=35.61 x-6.661$ & 0.9996 & $0.1-50$ & $0.008 \pm 0.16$ & $0.028 \pm 0.21$ & 4.17 & 4.82 \\
\hline HIS & $y=25.487 x-19.059$ & 0.9995 & $0.1-50$ & $0.007 \pm 0.18$ & $0.024 \pm 0.19$ & 4.01 & 3.94 \\
\hline TYR & $y=21.373 x-4.734$ & 0.9999 & $0.05-50$ & $0.010 \pm 0.02$ & $0.032 \pm 0.06$ & 1.59 & 1.56 \\
\hline SPD & $y=25.245 x+10.298$ & 0.9992 & $0.1-50$ & $0.011 \pm 0.25$ & $0.035 \pm 0.17$ & 7.27 & 9.52 \\
\hline SPM & $y=28.254 x-13.357$ & 0.9994 & $0.1-50$ & $0.014 \pm 0.20$ & $0.047 \pm 0.22$ & 7.00 & 12.66 \\
\hline
\end{tabular}

Table 3. Baseline values and recovery rates of the biogenic amines from crucian carp, bass, and turbot

\begin{tabular}{|c|c|c|c|c|c|c|c|c|c|c|c|c|}
\hline \multirow[b]{3}{*}{ Biogenic amine } & \multicolumn{4}{|c|}{ Crucian carp } & \multicolumn{4}{|c|}{ Sea bass } & \multicolumn{4}{|c|}{ Turbot } \\
\hline & \multirow{2}{*}{$\begin{array}{l}\text { Baseline value } \\
\qquad(\mathrm{mg} / \mathrm{kg})\end{array}$} & \multicolumn{3}{|c|}{ Recovery (\%) } & \multirow{2}{*}{$\begin{array}{l}\text { Baseline value } \\
\quad(\mathrm{mg} / \mathrm{kg})\end{array}$} & \multicolumn{3}{|c|}{ Recovery (\%) } & \multirow{2}{*}{$\begin{array}{l}\text { Baseline value } \\
\qquad(\mathrm{mg} / \mathrm{kg})\end{array}$} & \multicolumn{3}{|c|}{ Recovery (\%) } \\
\hline & & $2 \mathrm{mg} / \mathrm{kg}$ & $10 \mathrm{mg} / \mathrm{kg}$ & $20 \mathrm{mg} / \mathrm{kg}$ & & $2 \mathrm{mg} / \mathrm{kg}$ & $10 \mathrm{mg} / \mathrm{kg}$ & $20 \mathrm{mg} / \mathrm{kg}$ & & $2 \mathrm{mg} / \mathrm{kg}$ & $10 \mathrm{mg} / \mathrm{kg}$ & $20 \mathrm{mg} / \mathrm{kg}$ \\
\hline TRY & $1.66 \pm 0.01$ & $112.70 \pm 6.97$ & $73.14 \pm 1.28$ & $100.93 \pm 9.68$ & ND & $68.62 \pm 3.79$ & $88.39 \pm 1.95$ & $88.21 \pm 1.57$ & ND & $60.62 \pm 6.39$ & $59.91 \pm 2.54$ & $98.60 \pm 5.60$ \\
\hline 2-PHE & $6.78 \pm 0.11$ & $122.37 \pm 1.73$ & $106.28 \pm 2.76$ & $94.45 \pm 4.06$ & $9.58 \pm 0.66$ & $26.68 \pm 2.80$ & $78.33 \pm 2.46$ & $78.31 \pm 4.94$ & $0.85 \pm 0.34$ & $92.22 \pm 13.75$ & $109.44 \pm 5.26$ & $90.43 \pm 2.56$ \\
\hline PUT & $8.22 \pm 0.33$ & $102.23 \pm 0.71$ & $98.47 \pm 1.42$ & $99.08 \pm 5.33$ & $4.85 \pm 0.08$ & $86.51 \pm 1.36$ & $100.00 \pm 0.03$ & $97.28 \pm 3.33$ & $0.87 \pm 0.08$ & $117.57 \pm 6.33$ & $111.56 \pm 2.41$ & $106.46 \pm 4.23$ \\
\hline CAD & $5.22 \pm 0.01$ & $94.37 \pm 1.05$ & $98.35 \pm 0.84$ & $97.34 \pm 6.01$ & $4.57 \pm 0.08$ & $78.89 \pm 0.77$ & $89.52 \pm 1.18$ & $93.30 \pm 2.19$ & $0.25 \pm 0.02$ & $100.99 \pm 6.07$ & $103.54 \pm 1.02$ & $101.59 \pm 4.86$ \\
\hline HIS & $6.03 \pm 0.13$ & $102.51 \pm 1.47$ & $108.56 \pm 4.83$ & $100.64 \pm 4.28$ & $3.05 \pm 0.21$ & $99.46 \pm 4.34$ & $97.09 \pm 0.52$ & $97.20 \pm 1.99$ & $1.28 \pm 0.12$ & $99.33 \pm 3.24$ & $101.32 \pm 1.31$ & $100.51 \pm 5.32$ \\
\hline TYR & $0.45 \pm 0.01$ & $107.72 \pm 0.64$ & $96.80 \pm 0.70$ & $101.48 \pm 4.85$ & ND & $100.45 \pm 0.63$ & $96.10 \pm 2.35$ & $98.61 \pm 1.37$ & ND & $76.28 \pm 1.73$ & $93.99 \pm 1.28$ & $93.81 \pm 4.75$ \\
\hline SPD & $15.10 \pm 0.81$ & $168.27 \pm 4.33$ & $117.69 \pm 0.85$ & $121.39 \pm 4.96$ & $8.48 \pm 0.19$ & $84.99 \pm 3.32$ & $110.84 \pm 1.90$ & $98.23 \pm 5.10$ & $3.00 \pm 0.02$ & $112.70 \pm 1.86$ & $119.37 \pm 8.36$ & $111.24 \pm 4.59$ \\
\hline SPM & $20.32 \pm 0.64$ & $140.62 \pm 0.26$ & $123.50 \pm 1.49$ & $111.74 \pm 9.84$ & $17.20 \pm 0.37$ & $111.63 \pm 6.01$ & $74.69 \pm 1.82$ & $78.03 \pm 7.71$ & $19.26 \pm 0.06$ & $162.20 \pm 2.45$ & $104.56 \pm 1.08$ & $99.92 \pm 4.38$ \\
\hline
\end{tabular}

ND, not detected. 

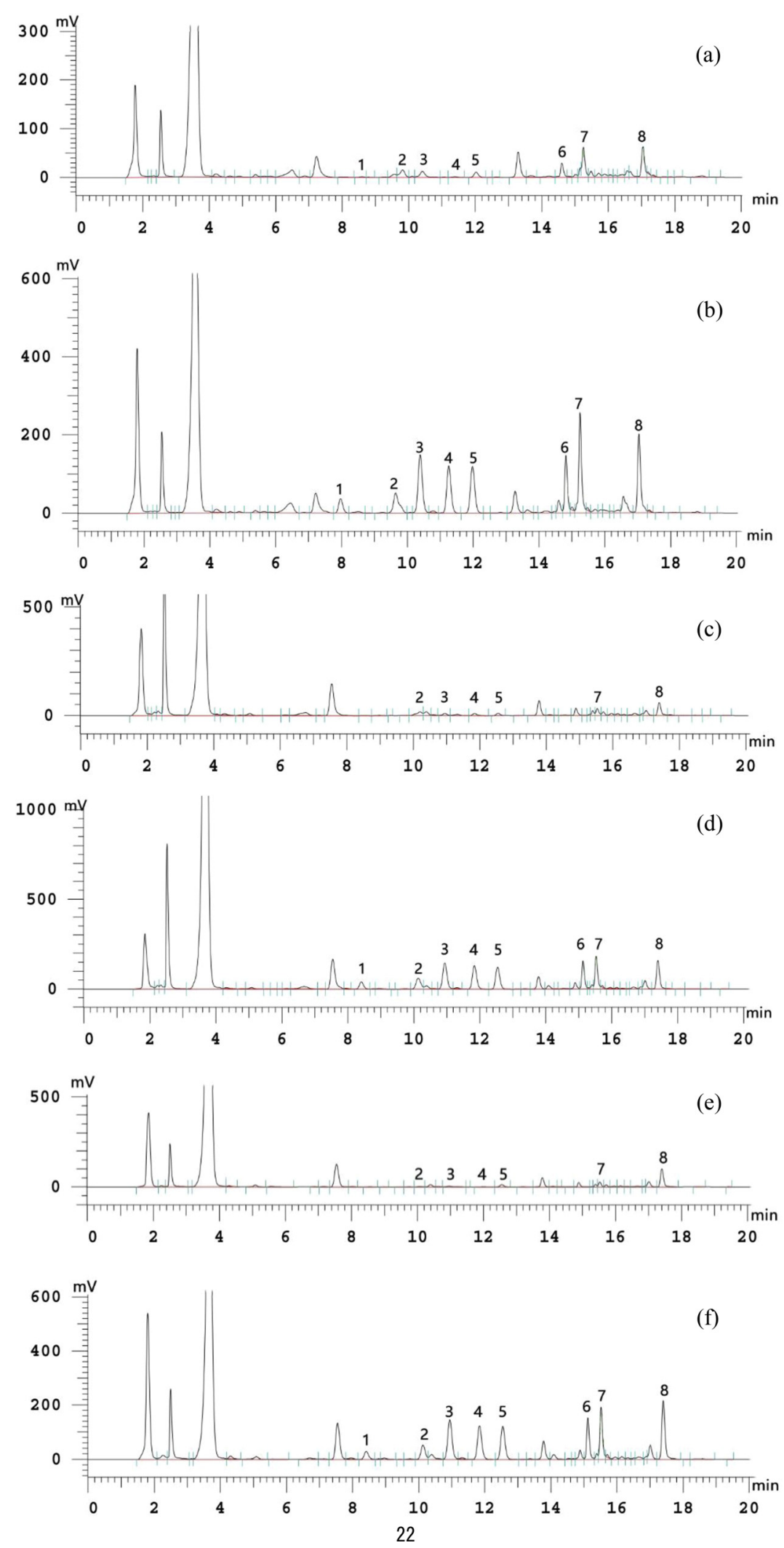

Fig. 3. Chromatograms of blank and spiked samples (20 mg/kg). (a) crucian carp, (b) spiked crucian carp, (c) sea bass, (d) spiked sea bass, (e) turbot, (f) spiked turbot. 1: TRY, 2: 2-PHE, 3: PUT, 4: CAD, 5: HIS, 6: TYR, 7: SPD, 8: SPM 

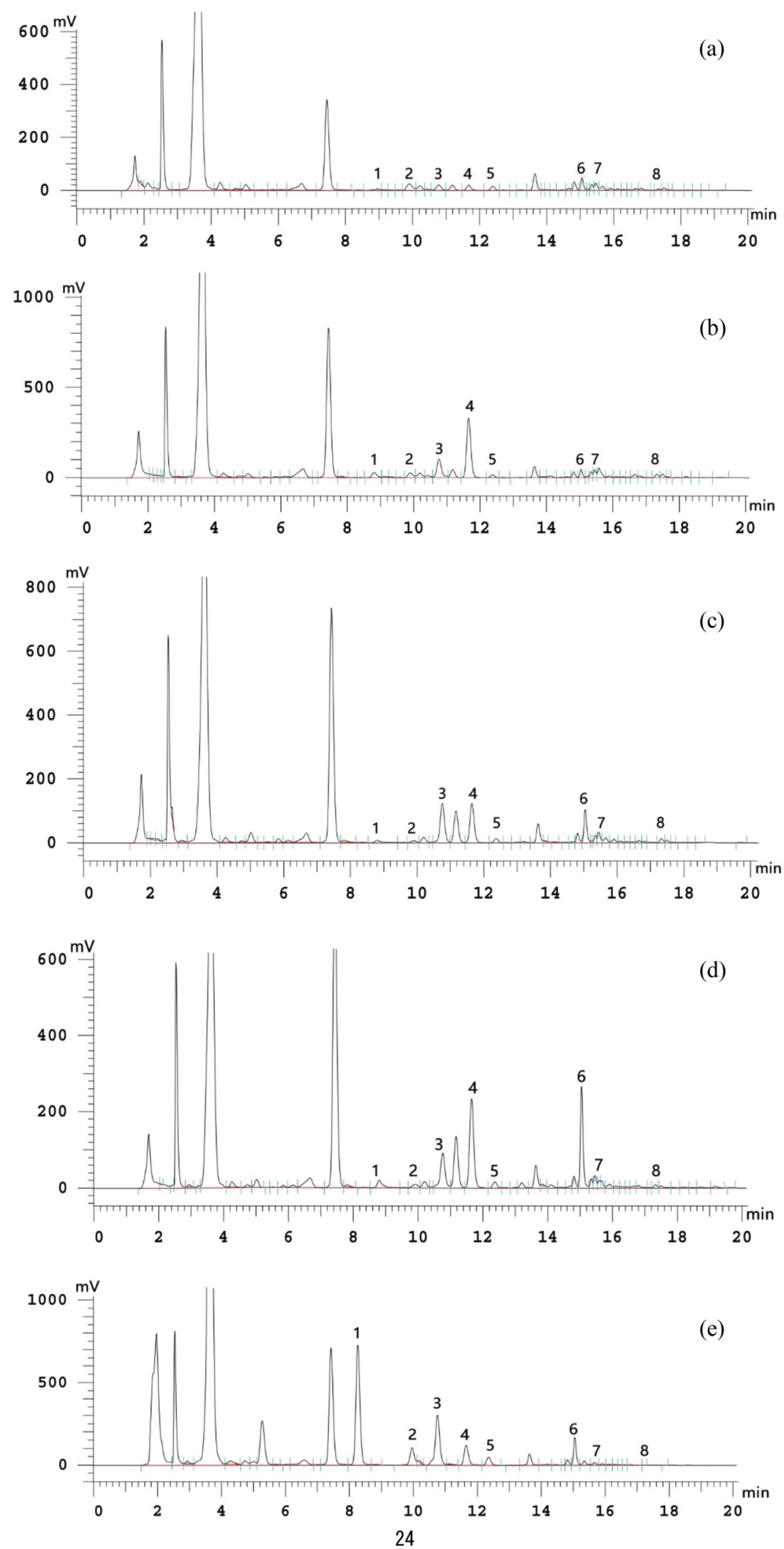

Fig. 4. Chromatograms of 5 kinds of fermented aquatic products. (a) Canned anchovies (Ganzhu), (b) Canned anchovies (Yuehua), (c) Canned saury (Kaixipopo), (d) Canned yellow croaker (Kaixipopo), (e) Shrimp paste (Lijinji). 1: TRY, 2: 2-PHE, 3: PUT, 4: CAD, 5: HIS, 6: TYR, 7: SPD, 8: SPM 
Table 4. The concentrations of eight biogenic amines in five commercial fermented aquatic products

\begin{tabular}{lccccccccc}
\hline BAs (mg/kg) & TRY & 2-PHE & PUT & CAD & HIS & TYR & SPD & SPM & Total \\
\hline $\begin{array}{l}\text { Canned anchovies } \\
\quad(\text { Ganzhu) }\end{array}$ & $2.31 \pm 0.00$ & $9.23 \pm 0.28$ & $10.53 \pm 0.07$ & $9.72 \pm 0.02$ & $6.24 \pm 0.18$ & $6.75 \pm 0.36$ & $11.16 \pm 0.49$ & $13.53 \pm 0.39$ & 69.46 \\
$\begin{array}{l}\text { Canned anchovies } \\
\quad(Y u e h u a)\end{array}$ & $2.36 \pm 0.08$ & $12.91 \pm 0.32$ & $22.69 \pm 0.34$ & $59.55 \pm 2.22$ & $6.53 \pm 0.08$ & $7.20 \pm 0.31$ & $13.16 \pm 2.59$ & $15.75 \pm 0.29$ & 140.15 \\
$\begin{array}{l}\text { Canned saury } \\
\quad(\text { Kaixipopo) }\end{array}$ & $2.49 \pm 0.11$ & $8.90 \pm 0.34$ & $24.11 \pm 0.10$ & $25.43 \pm 0.13$ & $6.15 \pm 0.04$ & $14.67 \pm 0.42$ & $10.92 \pm 0.24$ & $12.72 \pm 0.11$ & 105.39 \\
$\begin{array}{l}\text { Canned yellow } \\
\text { croaker (Kaixipopo) }\end{array}$ & $2.73 \pm 0.07$ & $9.03 \pm 0.54$ & $20.97 \pm 0.15$ & $43.26 \pm 0.64$ & $6.68 \pm 0.06$ & $35.69 \pm 0.55$ & $11.47 \pm 0.46$ & $12.49 \pm 0.10$ & 142.32 \\
$\begin{array}{l}\text { Shrimp paste } \\
\text { (Lijinji) }\end{array}$ & $313.49 \pm 2.23$ & $5.69 \pm 0.15$ & $53.60 \pm 1.65$ & $26.95 \pm 0.73$ & $12.29 \pm 0.04$ & $22.44 \pm 0.07$ & $9.96 \pm 0.21$ & $11.33 \pm 0.00$ & 455.75 \\
\hline
\end{tabular}

Table 5. Summary of HPLC methods for the determination of biogenic amines in aquatic products

\begin{tabular}{|c|c|c|c|c|c|c|c|c|}
\hline Analytes & Sample & $\begin{array}{c}\text { Time required for sample } \\
\text { preparation and } \\
\text { derivatization }\end{array}$ & Detection & $\begin{array}{l}\text { Analysis } \\
\text { time }\end{array}$ & Linear range & LOD & LOQ & Reference \\
\hline $\begin{array}{l}\text { TRY, PHE, PUT, CAD, HIS, } \\
\text { TYR, SPD, SPM }\end{array}$ & $\begin{array}{l}\text { Various aquatic } \\
\text { products }\end{array}$ & $53 \mathrm{~min}$ & UV (254 nm) & $18 \mathrm{~min}$ & $\begin{array}{l}0.1-50 \\
\mathrm{mg} / \mathrm{kg}\end{array}$ & $\begin{array}{l}0.007-0.021 \\
\mathrm{mg} / \mathrm{kg}\end{array}$ & $\begin{array}{c}0.024-0.069 \\
\mathrm{mg} / \mathrm{kg}\end{array}$ & This article \\
\hline $\begin{array}{l}\text { PUT, PHE, HIS, CAD, HEX, } \\
\text { TYR, SPD, SPM, ES }\end{array}$ & $\begin{array}{l}\text { Several food } \\
\text { samples }\end{array}$ & $96 \mathrm{~min}$ & $\begin{array}{c}\text { FLD }\left(\lambda_{\mathrm{EX}}=270 \mathrm{~nm},\right. \\
\left.\lambda_{\mathrm{EM}}=430 \mathrm{~nm}\right)\end{array}$ & $42 \mathrm{~min}$ & $\begin{array}{c}0.005-2.5 \\
\mu \mathrm{mol} / \mathrm{L}\end{array}$ & $\begin{array}{c}0.27-0.69 \\
\mu \mathrm{g} / \mathrm{L}\end{array}$ & $\begin{array}{l}\text { Not } \\
\text { mentioned }\end{array}$ & [11] \\
\hline $\begin{array}{l}\text { TRY, PUT, CAD, HIS, TYR, } \\
\text { SPD, SPM }\end{array}$ & Yulu & $130 \mathrm{~min}$ & $\begin{array}{l}\mathrm{FLD}\left(\lambda_{\mathrm{EX}}=350 \mathrm{~nm}\right. \\
\left.\quad \lambda_{\mathrm{EM}}=520 \mathrm{~nm}\right)\end{array}$ & $33 \mathrm{~min}$ & $\begin{array}{c}0.25-50 \\
\mathrm{mg} / \mathrm{kg}\end{array}$ & $\begin{array}{c}0.38-2.99 \\
\mathrm{mg} / \mathrm{kg}\end{array}$ & $\begin{array}{c}1.17-9.06 \\
\mathrm{mg} / \mathrm{kg}\end{array}$ & {$[12]$} \\
\hline $\begin{array}{l}\text { TRY, PUT, CAD, HIS, TYR, } \\
\text { SPD }\end{array}$ & Grass carp & $140 \mathrm{~min}$ & UV $(254 \mathrm{~nm})$ & $30 \mathrm{~min}$ & $\begin{array}{l}0.5-100 \\
\mu \mathrm{g} / \mathrm{mL}\end{array}$ & $\begin{array}{c}\text { Not } \\
\text { mentioned }\end{array}$ & $\begin{array}{c}\text { Not } \\
\text { mentioned }\end{array}$ & [13] \\
\hline $\begin{array}{l}\text { TRY, PHE, PUT, CAD, HIS, } \\
\text { TYR, SPD, SPM }\end{array}$ & Catfish & $105 \mathrm{~min}$ & UV (254 nm) & $37.5 \mathrm{~min}$ & $\begin{array}{l}2-100 \\
\mathrm{mg} / \mathrm{L}\end{array}$ & $\begin{array}{c}\text { Not } \\
\text { mentioned }\end{array}$ & $\begin{array}{c}\text { Not } \\
\text { mentioned }\end{array}$ & {$[16]$} \\
\hline $\begin{array}{l}\text { TRY, PHE, PUT, CAD, HIS, } \\
\text { TYR, SPD, SPM }\end{array}$ & Saury & $107 \mathrm{~min}$ & UV $(254 \mathrm{~nm})$ & $15 \mathrm{~min}$ & $\begin{array}{l}1-100 \\
\mathrm{mg} / \mathrm{kg}\end{array}$ & $\begin{array}{c}0.02-0.17 \\
\mathrm{mg} / \mathrm{kg}\end{array}$ & $\begin{array}{c}0.067-0.57 \\
\mathrm{mg} / \mathrm{kg}\end{array}$ & [26] \\
\hline $\begin{array}{l}\text { TRY, PHE, PUT, CAD, HIS, } \\
\text { TYR, SPD, SPM, } \\
\text { Octopamine, Serotonin }\end{array}$ & $\begin{array}{l}\text { Various aquatic } \\
\text { products }\end{array}$ & $95 \min$ & UV (254 nm) & $30 \mathrm{~min}$ & $\begin{array}{c}0.2-10 \\
\mathrm{mg} / \mathrm{L}\end{array}$ & $\begin{array}{l}0.8-5 \\
\mu \mathrm{g} / \mathrm{g}\end{array}$ & $30 \mu \mathrm{g} / \mathrm{g}$ & [27] \\
\hline
\end{tabular}


Meanwhile, the $10 \mathrm{mg} / \mathrm{kg}$ standard mixed solution was derived in parallel twice and injected three times respectively to calculated the RSD values represented the intra-batch difference. Another set of RSD value was calculated based on the data of $10 \mathrm{mg} / \mathrm{kg}$ standard mixed solution injected four times in different batches to represent the inter-batch difference. All the RSD values obtained were less than 13\%, indicating that the method had good repeatability.

Accuracy evaluation. $100 \mu \mathrm{L}, 500 \mu \mathrm{L}$, and $1 \mathrm{~mL}$ of $100 \mathrm{mg} /$ $\mathrm{L}$ mixed standard solution of biogenic amines were added to $5 \mathrm{~g}$ of homogenized fish meat samples respectively to obtain spiked samples of crucian carp, sea bass, and turbot with spiked concentrations of 2.0, 10.0, and $20.0 \mathrm{mg} / \mathrm{kg}$. At the same time, the baseline values of biogenic amines in three fish backgrounds were determined to evaluate the recovery rates at different addition levels. As shown in Table 3, the recovery rates of eight biogenic amines were basically between 68 and $123 \%$ while the RSDs were less than 15\%, indicating that the method was adaptable to a variety of aquatic products. The liquid chromatograms of blank samples and spiked samples $(20 \mathrm{mg} / \mathrm{kg})$ were shown in Fig. 3.

\section{Application to real samples}

Five kinds of fermented aquatic products, including four kinds of canned fish and one shrimp paste product from the local supermarket were selected to validate the application of the developed HPLC method. As shown in Table 4 and Fig. 4, the types, contents and proportions of biogenic amines in the five fermented aquatic products were different. The total content of biogenic amines in shrimp paste was the highest, which had reached to $455.75 \mathrm{mg} / \mathrm{kg}$. The high content of biogenic amine was closely related to the processing of shrimp paste that needed a long time of fermentation [22]. The total biogenic amines in the other four types of fermented fish products were range from 69.46 to $142.32 \mathrm{mg} / \mathrm{kg}$, which were not significantly different from similar studies [13, 23]. TRY was the most abundant biogenic amine in shrimp paste. CAD and PUT were the main biological amines in fermented canned fish products, which is consistent with existing research $[24,25]$. However, the contents of HIS, which was the commonly detected index in food safety standards, were range from 6.15 to 12.29 $\mathrm{mg} / \mathrm{kg}$. The levels of biogenic amines in the detected fermented aquatic products were lower than the relevant limit standards, indicating that not only HIS, but also CAD, PUT, TRY, and the total biogenic amines should be considered when formulating and improving relevant regulations.

\section{CONCLUSION}

In this study, a HPLC for the simultaneous determination of eight biogenic amines in aquatic products, which was much more efficient and sensitive (Table 5) to the existing HPLC, was developed and validated. the eight biogenic amines could be well separated in 18 mins with a time saving simple and easy to operate derivation procedure by $\mathrm{Dns}-\mathrm{Cl}$. The validation and application to real samples indicated that the developed method could accurately detect the biogenic amines in the fermented aquatic products at a low concentration.

\section{NOTES}

The authors declare no competing financial interest.

\section{ACKNOWLEDGMENT}

This work was supported by the National Key R\&D Program of China (2018YFD0901005).

\section{REFERENCES}

1. Chung, M.; Davaatseren, M.; Doeun, D. Food Sci. Biotechnol. 2017, 26, 1463-74.

2. Zhang, J.; Liu, Z.; Hu, Y.; Fang, Z.; Chen, J.; Wu, D.; Ye, X. J. Food Sci. Technol. 2011, 48, 69-75.

3. ten Brink, B.; Damink, C.; Joosten, H. M.; Huis in't Veld, J. H. Int. J. Food Microbiol. 1990, 11, 73.

4. Donthuan, J.; Yunchalard, S.; Srijaranai, S. Analyt. Method 2014, 6, 1128.

5. Tao, Z.; Sato, M.; Nakano, T.; Tan, Z.; Han, Y.; Yamaguchi, T. Food Control 2011, 22, 1154-7.

6. Li, C.; Jiang, X.; Hou, X. Microchem. J. Devoted to the Application of Microtechniques in all Branches of Science 2015, 119, 108-13.

7. Jastrzebska, A.; Piasta, A.; Szlyk, E. J. Analyt. Chem. 2015, 70, 1131-8.

8. An, D.; Chen, Z.; Zheng, J.; Chen, S.; Wang, L.; Huang, Z.; Weng, L. Food Chem. 2015, 168, 1-6.

9. Leng, P.; Zhao, F.; Yin, B.; Ye, B. ChemComm (Cambridge, England). 2015, 51, 8712-4.

10. Henao-Escobar, W.; Del Torno-de Román, L.; Domínguez-Renedo, O.; Alonso-Lomillo, M. A.; Arcos-Martínez, M. J. Food Chem. 2016, 190, 818-23.

11. Li, G.; Dong, L.; Wang, A.; Wang, W.; Hu, N.; You, J. Lwt Food Sci. Technol. 2014, 355-61.

12. Jiang, W.; Xu, Y.; Li, C.; Dong, X.; Wang, D. Food Addit. Contam. B 2014, 7, 25-9.

13. Zeng, N.; Jiang, Y.; Chen, L.; Zhao, L.; Bai, C.; Yuan, M.; Wei, Y. Sci. Technol. Food Ind. 2016, 37, 117-22.

14. Chen, X.; Hu, Y.; Li, L.; Huang, Z. Chin. J. Food Sci. 2015, 15, 211-7.

15. Chinese National Food Safety Standard. GB 5009.208-2016. Determination of biogenic amines in food.

16. Zhao, Q.; Deng, J.; Yang, X.; Li, L.; Hu, X.; Wang, J.; Wu, Y.; Wei, Y. Sci. Technol. Food Ind. 2018, 39, 260-7.

17. Saaid, M.; Ali, A. S. M.; Saad, B.; Hashim, N. H.; Saleh, M. I. Food Chem. 2009, 113, 1356-62.

18. Kirschbaum, J., Rebscher, K., Brückner, H. J. Chromatogr. A 2000, 517-30.

19. Mazzotti, F.; Di Donna, L.; Napoli, A.; Aiello, D.; Siciliano, C.; Athanassopoulos, C. M. Sindona, G. J. Mass Spectrometry: JMS 2014, 49, 802-10. 
20. Self, R. L.; Wu, W. J. Food Composit. Anal. 2012, 27, 169-73.

21. Simat, V.; Dalgaard, P. Lebensmittel-Wissenschaft Und-Technologie 2011, 44, 399-406.

22. Dai, P.; Li, Z.; Pan, Y.; Liu, Y.; Lin, J. Food Technol. 2013, 38, 286-90.

23. Wu, Y.; Chen, Y.; Li, L.; Yang, X.; Lin, W.; Yang, S. J. Fish. 2015, $1577-86$.
24. Rabie, M.; Simon-Sarkadi, L.; Siliha, H.; El-seedy, S.; El Badawy, A. Food Chem. 2009, 115, 635-8.

25. Mah, J.; Han, H.; Oh, Y.; Kim, M.; Hwang, H. Food Chem. 2002, 79, 239-43.

26. Tian, X.; Liu, H.; Li, C.; Zhang, L.; Cao, M.; Liu, G. J. Food Safety Quality Inspect. 2017, 8, 1171-8.

27. Ding, Z.; Liu, C.; Chen, D.; Tang, Y.; Yong, K.; Fang, X. J. Anal. Test. 2006, 59-62.

Open Access. This is an open-access article distributed under the terms of the Creative Commons Attribution-NonCommercial 4.0 International License (https:// creativecommons.org/licenses/by-nc/4.0/), which permits unrestricted use, distribution, and reproduction in any medium for non-commercial purposes, provided the original author and source are credited, a link to the CC License is provided, and changes - if any - are indicated. 